\title{
Growth pattern of children in a Moslem semirural community near Jerusalem
}

\author{
HAVA PALTI, BOSCO STROZZI, AND MALKA AVITZOUR \\ From the Department of Social Medicine, Hadassah Medical Organisation Hebrew University and Hadassah \\ School of Public Health and Community Medicine, Jerusalem, Israel
}

SUMMARY The growth pattern of infants from birth to 2 years of age was studied in a homogenous Moslem semirural community near Jerusalem. The weight of the study population was compared with that of children from a western neighbourhood in Jerusalem and the National Centre of Health Statistics standard. The Abu Ghosh children are lighter than the Jerusalem and the National Centre of Health Statistics populations at birth and subsequently at 1, 6, 12, and 24 months of age. The percentage of weight gain between any two measurements at the various ages is slightly lower than that of the Jerusalem population. There is no decline in percentage of weight gain after weaning. Birthweight has accounted for a high percentage of explained variance of weight at 6 months $(14 \cdot 4 \%)$, but explained only $1 \cdot 2 \%$ of variance at 24 months. The percentage of girls below the 10th centile was less than that of boys. The genetic and environmental effects on growth as well as the effect of the mother and child health services on the child rearing patterns of the populations are discussed.

The purpose of this study is to determine the physical growth from birth to 2 years of children from a Moslem Arab village in the vicinity of Jerusalem and to compare their growth pattern with that of Jewish children from a low and middle class community in Jerusalem and with the National Centre of Health Statistics (NCHS) ${ }^{1}$ standards based on children from the United States.

\section{Material and methods}

Abu Ghosh is a Moslem Arab village with about 3000 inhabitants in the hilly region about $12 \mathrm{~km}$ from Jerusalem. An old and well-established community, it traces its origin to a single family about $\mathbf{4 0 0}$ years ago, thus being a genetically homogenous population. The houses are made of stone; there is electricity and running water. All families have vegetable gardens. Most men work outside the village in Jerusalem or neighbouring settlements. The social class distribution indicates homogeneity-almost all belong to the semi-skilled or unskilled working class. The educational standard of the population by years of schooling indicates that $7 \%$ are illiterate, $13 \%$ have one to two years of schooling, $75 \%$ eight to nine years, and $5 \% 10$ or more years. The distribution of fathers' and mothers' educational standard is similar. There is a mother and child health $(\mathrm{MCH})$ centre in the village where preventive care is provided almost free of charge $(\$ 3$ a year). The public health nurse is available every day, while the paediatrician and gynaecologist work in the MCH centre once a week. Most of the population has prepaid insurance for medical care. There is in the village a clinic of the "Kupat Holim" Sick Fund of the General Federation of Labour in Israel that provides curative care.

A total of 480 babies born between January 1972 and August 1978 were included in the study population. Of those, 15 died during infancy. During 1972-5 there were 12 deaths (infant mortality rate $=42 / 1000$ ) and during $1976-8$ there were three (infant mortality rate $=15 / 1000$ ). Yearly rates were not calculated because of the small size of the population. The average number of visits to the $\mathrm{MCH}$ centre during the first year of life was 14 visits per child. On average, pregnant women were seen by a nurse five times and by a doctor three times. The same doctor and nurse have worked at the $\mathrm{MCH}$ centre for several years. All weight and length measurements were taken by the same nurse. Demographic and anthropometric data as well as history of pregnancy were extracted from the personal file of the mother and child. The NCHS 
weight and length percentiles were interpolated by us into weekly intervals and into 10 percentile categories, and then used to determine age and sex specific percentiles for weight and length measurements. The above-mentioned method for calculating percentiles was used for the Jerusalem population as well, which was studied by the same team. ${ }^{2}$ Length measurements were available only for the 1-month age group for the Abu Ghosh population.

The $\mathrm{Z}$ test was used to test differences between means. Since five comparisons were done for each sex the critical $p$ value considered as significant was 0.001 . Analysis of variance ${ }^{3}$ was used to appraise the contribution of birthweight, birth order, and educational standard of the mother on weight by each of the independent variables.

\section{Findings}

Measurements were available for 404 children born to 204 mothers: over $84 \%$ were seen at each of the medical examinations at $1,3,6$, and 12 months and about $40 \%$ were seen at 2 years. The intraclass correlation coefficient ${ }^{4}$ for the weight was calculated for families with two, three, four, and five children (at $1,3,6,12$, and 24 months of age) (table 1). The

Table 1 Intraclass correlation coefficients for weight, by size of sibship at 1, 3, 6, 12, and 24 months of age

\begin{tabular}{lllllll}
\hline \multicolumn{7}{l}{ Age (months) } \\
\cline { 3 - 7 } Siblings & $N$ & 1 & 3 & 6 & 12 & 24 \\
\hline 2 & 62 & 0.01 & 0.32 & 0.00 & 0.01 & 0.01 \\
3 & 34 & 0.01 & 0.32 & 0.00 & 0.01 & 0.01 \\
4 & 15 & 0.01 & 0.12 & 0.01 & 0.07 & 0.13 \\
5 & 6 & 0.03 & 0.01 & 0.03 & 0.37 & 0.14 \\
\hline
\end{tabular}

$\mathbf{N}=$ Number of families in group. intraclass correlation coefficients were very low at each age (range $0 \cdot 00-0 \cdot 37$ ). The low correlations indicate that the variance of weight within the groups is similar to that between groups of children belonging to different families. The low correlations allow for inclusion of all children from the same family in the sample. Only three out of 20 correlations were statistically significant.

Table 2 presents the mean weight by age and sex of the Abu Ghosh and the Jerusalem children at birth, $1,6,12$, and 24 months. The mean weight of the Abu Ghosh children is lighter at each age; the differences are statistically significant.

The children in Abo Ghosh were also shorter. The mean length at 1 month for the Abu Ghosh boys is $52.4 \mathrm{~cm} \mathrm{SD} 2.3$ and girls $51.6 \mathrm{~cm} \mathrm{SD} \mathrm{2.3.} \mathrm{The} \mathrm{mean}$ length for the Jerusalem population is $53.3 \mathrm{SD} 2.4$ and 52.9 SD 2.1 respectively. The differences are statistically significant for girls only $(p=0.001)$.

Comparison of the Abu Ghosh children with the United States reference standard indicates a gradual increase in the percentage of children below the 10th centile and a shift of the total distribution towards the lower centile categories with age. The trend is similar for boys and girls (fig 1). To assess whether the children under the 10th percentile are between the 10 th and 3 rd percentile, or below the 3rd percentile, an additional classification was used, as recommended by the World Health Organisation. ${ }^{5}$ The service charts for populations with large number of children below the lower centiles include three additional channels: between the 3rd percentile and $-3 \mathrm{SD}$, between -3 and $-4 \mathrm{SD}$, and less than -4 SD. The results indicate that most children below the 10th centile belong to the category between the 10 th and the 3 rd percentile, a higher percentage than expected belong to the category between the 3rd to -3 SD especially at 12 months of age for both sexes.

Table 2 Mean weights of Abu Ghosh and Jerusalem children by age and sex

\begin{tabular}{|c|c|c|c|c|c|c|c|}
\hline \multirow[b]{2}{*}{$\begin{array}{l}\text { Age } \\
\text { (months) }\end{array}$} & \multicolumn{3}{|c|}{ Abu Ghosh (Moslem) } & \multicolumn{3}{|c|}{ Jerusalem (Jewish)* } & \multirow[b]{2}{*}{$\boldsymbol{p}$} \\
\hline & $\begin{array}{l}\text { Mean } \\
\text { weight (g) }\end{array}$ & $S D$ & $N$ & $\begin{array}{l}\text { Mean } \\
\text { weight (g) }\end{array}$ & $S D$ & $N$ & \\
\hline \multicolumn{8}{|l|}{ Boys } \\
\hline $\begin{array}{c}\text { Birth } \\
1 \\
6 \\
12 \\
24\end{array}$ & $\begin{array}{r}3140 \\
4010 \\
7350 \\
9300 \\
11420\end{array}$ & $\begin{array}{r}540 \\
730 \\
1082 \\
1200 \\
1140\end{array}$ & $\begin{array}{r}210 \\
191 \\
190 \\
184 \\
86\end{array}$ & $\begin{array}{r}3230 \\
4070 \\
7720 \\
9970 \\
12330\end{array}$ & $\begin{array}{r}500 \\
590 \\
830 \\
1100 \\
1360\end{array}$ & $\begin{array}{l}432 \\
339 \\
264 \\
234 \\
208\end{array}$ & $\begin{array}{l}0.001 \\
\text { NS } \\
0.001 \\
0.001 \\
0.001\end{array}$ \\
\hline \multicolumn{8}{|l|}{ Girls } \\
\hline $\begin{array}{c}\text { Birth } \\
1 \\
6 \\
12 \\
24\end{array}$ & $\begin{array}{r}2480 \\
3720 \\
6770 \\
8700 \\
10930\end{array}$ & $\begin{array}{r}520 \\
560 \\
980 \\
1100 \\
1380\end{array}$ & $\begin{array}{r}191 \\
160 \\
163 \\
158 \\
86\end{array}$ & 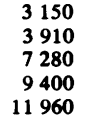 & $\begin{array}{r}510 \\
520 \\
830 \\
1130 \\
1470\end{array}$ & $\begin{array}{l}440 \\
346 \\
278 \\
256 \\
234\end{array}$ & $\begin{array}{l}0.007 \\
0.016 \\
0.001 \\
0.001 \\
0.001\end{array}$ \\
\hline
\end{tabular}

"Low and middle class children of a western neighbourhood in Jerusalem.

$\mathbf{N}=$ Number of children. 


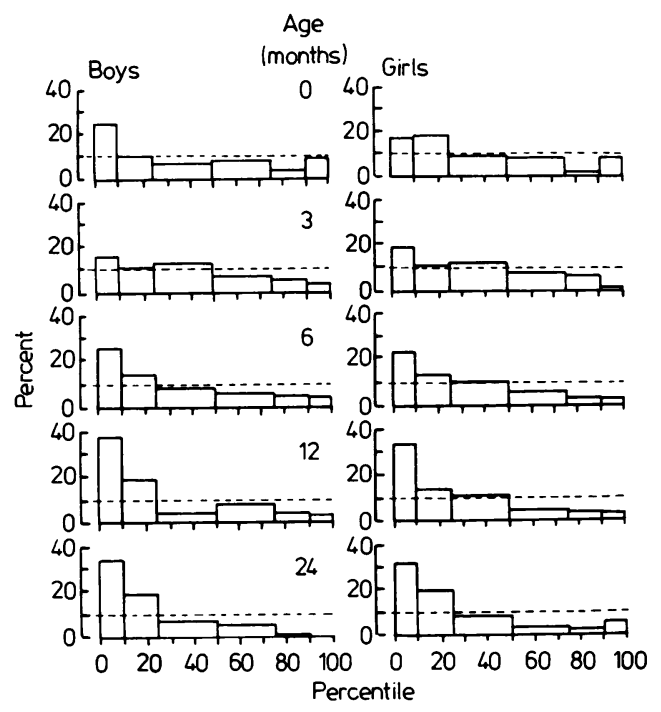

Fig 1 Percentage distribution of weight percentiles by age and sex. A comparison with the NCHS standard. Broken line indicates expected percentage.

In the category of $-3 \mathrm{SD}$ to $-4 \mathrm{SD}$ there are only $0-2 \%$ of boys and $0-3 \%$ of girls and none of the population are below -4 SD (table 3 ).

The length measurements were available for the first month only. The weight for length percentile was calculated. Only $5 \%$ of the babies were below the 25 th centile, $84 \%$ were between $25-75$ th, and $11 \%$ were above the 75 th percentile weight for length.

The percentage of weight gain from $0-1,1-3,3-6$, 6-12, and 12-24 months shows the same trend as that of the Jerusalem children and is different from that of a population of children from low socioeconomic status in Lebanon ${ }^{6}$ (fig 2), where a steep decline in weight gain was noted from the age of 6 months to 24 months.

The contribution of birthweight, birth order, and mother's education to weight at 6,12 , and 24 months of age was analysed by the analysis of variance (table 4). The effect of birthweight on weight at 6 months

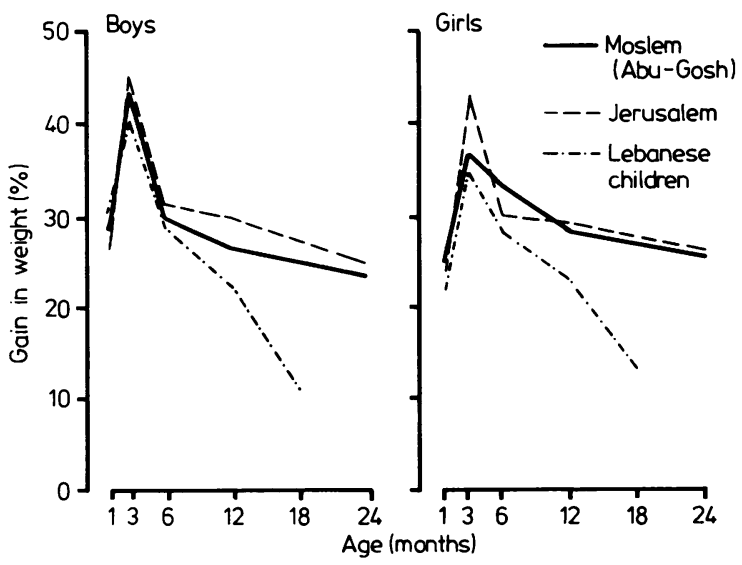

Fig 2 Percentage of weight gain of the Abu Ghosh, Jerusalem, and low social class Lebanese children by sex.

was highly significant $(F=9.909, p=0.001)$ and explained $14.4 \%$ of the variance, whereas no significant association was found between birthweight and weight at 1 and 2 years of age. Mother's educational level, defined by years of formal schooling, and birth order had no statistically significant effect on weight at any of the ages studied. The percentage of total explained variance decreased with age from 14.9 at 6 months to 3.1 at 24 months, mainly because the largest component of the explained variance at 6 months was attributable to birthweight (14.4), and at 24 months birthweight explained only $1.2 \%$ of the variance. Birth order contributed only $0.4-2 \%$ and mother's education $1 \cdot 2-1 \cdot 7 \%$ to the explained variance. In the analysis the sexes were combined since similar trends were noted for boys and girls where sexes were analysed separately.

\section{Discussion}

As the population of Abu Ghosh are descendants of one family frequent intermarriages have occurred through the generations. Since the genetic and

Table 3 Percentage of children between the 10th and - 4th percentile, and 3rd-3SD and between - 3SD and - 4SD and less than - 4SD for weight of the NCHS standard by age and sex

\begin{tabular}{|c|c|c|c|c|c|c|c|c|}
\hline \multirow[b]{3}{*}{$\begin{array}{l}\text { Age } \\
\text { (months) }\end{array}$} & \multicolumn{8}{|c|}{ Weight percentiles } \\
\hline & \multicolumn{4}{|l|}{ Boys } & \multicolumn{4}{|l|}{ Girls } \\
\hline & $10-4 t h$ & $3 r d-3 S D$ & $<3 S D-4 S D$ & $\begin{array}{l}\text { Less than } \\
-4 S D\end{array}$ & $10-4 t h$ & $3 r d-3 S D$ & $<3 S D-4 S D$ & $\begin{array}{l}\text { Less than } \\
-4 S D\end{array}$ \\
\hline 3 & 12 & 2 & 0 & 0 & 13 & 3 & 2 & 0 \\
\hline 6 & 18 & 4 & 1 & 0 & 12 & 6 & 3 & 0 \\
\hline 12 & 35 & 13 & 2 & 0 & 28 & 14 & 3 & 0 \\
\hline 24 & 36 & 8 & 0 & 0 & 36 & 7 & 0 & 0 \\
\hline
\end{tabular}


Table 4 Contribution of birthweight, mother's educational standard, and birth order to weight at 6, 12, and 24 months of age; analysis of variance

\begin{tabular}{|c|c|c|c|c|}
\hline Age (months) & Factor & $F$ & $p$ & \% of explained variance \\
\hline 6 & $\begin{array}{l}\text { Birthweight } \\
\text { Mother's education } \\
\text { Birth order } \\
\text { Total } \\
\text { N }\end{array}$ & $\begin{array}{r}9 \cdot 909 \\
1 \cdot 717 \\
0 \cdot 509 \\
241\end{array}$ & $\begin{array}{l}0.004 \\
\text { NS } \\
\text { NS }\end{array}$ & $\begin{array}{r}14.4 \\
1.2 \\
0.4 \\
14.9\end{array}$ \\
\hline 12 & $\begin{array}{l}\text { Birthweight } \\
\text { Mother's education } \\
\text { Birth order } \\
\text { Total } \\
\text { N }\end{array}$ & $\begin{array}{r}1 \cdot 743 \\
1 \cdot 741 \\
2 \cdot 163 \\
\\
241\end{array}$ & $\begin{array}{l}\text { NS } \\
\text { NS } \\
\text { NS }\end{array}$ & $\begin{array}{l}2.8 \\
1.7 \\
2.0 \\
6.1\end{array}$ \\
\hline 24 & $\begin{array}{l}\text { Birthweight } \\
\text { Mother's education } \\
\text { Birth order } \\
\text { Total } \\
\text { N }\end{array}$ & $\begin{array}{r}0.744 \\
1.625 \\
0.855 \\
\\
128\end{array}$ & $\begin{array}{l}\text { NS } \\
\text { NS } \\
\text { NS }\end{array}$ & $\begin{array}{l}1 \cdot 2 \\
1 \cdot 2 \\
0 \cdot 8 \\
3 \cdot 1\end{array}$ \\
\hline
\end{tabular}

df: Birthweight -4 ; mother's education -2 ; birth order -2 .

$\mathbf{N}=$ Number of children.

environmental background are similar for the families included in the study, we assumed that the correlations of weight at a certain age among siblings of the same family might not differ from the correlation of weights among peers from different families of the population. Therefore intraclass correlation coefficients were calculated for weight. Out of 20 correlations, 17 were low indicating that the siblings of the same family are not more homogenous regarding weight than the children from different families, thus confirming our hypothesis of a homogenous population and allowing inclusion of the siblings in the study.

The comparison of the mean weights of the Abu Ghosh children with a Jerusalem Jewish low and middle class population shows that the children of Abu Ghosh are lighter than those from Jerusalem. These differences may be due to genetic differences as well as environmental factors such as higher social class and educational standard of the parents of the Jerusalem children. In addition, Abu Ghosh is a semirural settlement in contrast to Jerusalem which is an urban area. Comparisons of urban with rural populations indicate taller stature of the urban child populations. $^{\text {? }}$

The comparison of the Abu Ghosh children with the NCHS standard showed a gradual shift of the weight percentile distribution toward the lower centile categories with an increase of the percentage of children below the 10th centile. Further breakdown of this category showed that most of the children below the 10th centile are actually between the 10th and the 3rd percentile; the percentage of children with a weight of less than -3 SD is somewhat higher than expected, but none belong to the extreme category of less than $4 \mathrm{SD}$. The weight percentile distribution of the Jerusalem Jewish children from birth to 24 months was almost similar to the weight distribution of the NCHS reference population. Comparison of the length of Jerusalem children with the NCHS standard indicated that at 12 and 24 months a high proportion of the Jerusalem population is below the 10 th percentile. ${ }^{2}$

Length data were available only for the 1-month-old children. The weight for length calculations showed that the Abu Ghosh children have appropriate weight for length. Deducing from this finding to subsequent ages it seems that the Abu Ghosh children are shorter and lighter than the NCHS reference population. The sub-classification of children below the 10th centile into more detailed categories indicates that almost none of the children are between -3 SD and -4 SD and none below -4 SD of the weight for each combination of age and sex studied. Thus despite the fact that a high percentage of children at 12 and 24 months are below the 10th centile, the weight deficit was not severe.

The growth of Arab children from Haifa at 12 months of age and at school age were compared with that of the NCHS standard and other ethnic groups in Israel. The Arab children were shorter and lighter. ${ }^{8} 9$

The NCHS reference standard for the first two years of life is based on a middle-class American population from the follow-up study of the Fels Institute. Differences between the reference population and the Abu Ghosh as well as the Jerusalem children may be due mainly to differences in environmental factors and to some extent to differences in genetic background.

The comparison of the weight gain of the Abu Ghosh children with that of the Jerusalem children shows a similar pattern, there is no steep decline in the Abu Ghosh children in weight gain around 6 months of age associated with weaning, as noted in 
developing countries. ${ }^{10-12}$ The lower birth weight of the Abu Ghosh children and the lower percentage weight gain at most age intervals explains the smaller mean weights at most age groups of the Abu Ghosh children, compared with the Jerusalem population.

From the analysis of variance it is apparent that birthweight has a statistically significant effect on weight during the first six months of life. Educational standard of the mother and birth order of the child had no statistically significant effect on weight at any of the ages studied, probably due to the similar feeding patterns and environmental conditions of the population. The above mentioned variables explained only a small percentage of the variance thus indicating that other factors not included in the analysis such as infections, or periods in hospital may have an effect; this needs further analysis.

It is of interest to note that the pattern of weight gain is similar in boys and girls. Harfouche ${ }^{6}$ described a deficit in length gain in girls as compared with boys among Lebanese children. Afaneh ${ }^{13}$ described the growth of Arab Moslem children from birth to 3 years old in a village on the West bank of the Jordan river. He noted that a significantly higher percentage of girls were below the 10th centile for weight and length than boys. The sex growth differential may indicate a difference in feeding practices of boys as compared with girls. Boys have higher priority than girls, as known from traditional societies. ${ }^{14}$ Owing to the differential behaviour in these societies malnutrition is more prevalent in girls.

The similar pattern of growth of girls and boys in the study population suggests that no discriminative pattern in feeding practices exists by sex. It may be due to the higher socioeconomic status of this population, meaning no lack of food. In addition, the population studied lives in the vicinity of Jerusalem where Western cultural and behavioural patterns predominate. Also the mother and child health services, which are regularly attended by the women during pregnancy and delivery, educate and instruct the mothers regarding child-rearing practices and survey the growth of the child closely through the first two years of life, thus affecting behaviour of the population regarding parent child interactions and promoting equalitarian behaviour toward girls and boys.

The fact that no statistically significant effect of educational standard and birth order were noted on weight could be explained by the homogeneity of social class and living conditions, the equal availability of health services, and the effect of those services on child-rearing practices.

We thank Dr Stark, the district health officer and the staff of the maternal and child health services of the district health office for their co-operation and help, and Professors JH Abramson and E Peritz for their advice.

\section{References}

${ }^{1}$ National Center of Health Statistics. Growth curves for children from birth-18 years. Washington, DC: US Department of Health, Education and Welfare, 1977. (Series 11 No 165.)

${ }^{2}$ Palti H, Adler B, Shamir Z, Kark SL. Community diagnosis of physical growth of infants based on monitoring in a routine preventive service. $J$ Epidemiol Community Health 1979; 33: 292-6.

${ }^{3}$ Nie NH, Hull CH, Jenkins JA, Steinbrenner K, Bent DH. Statistical package for social sciences (SPSS). New York: McGraw-Hill sc ed, 1975.

${ }^{4}$ Blalock HM Jr, Wicken PH. Intergroup process. New York: Free Press, 1979; 546-57.

${ }^{5}$ World Health Organisation. A growth chart for international use in maternal and child health. Geneva: WHO, 1978. (15BN 12-4-15.41296.)

${ }^{6}$ Harfouche JK. Growth and illness patterns of Lebanese infants. Beirut: Khayats, 1966.

${ }^{7}$ Eveleth PB. In: Falkner F, Tanner JM. Population differences in growth, environmental and genetic factors in human growth. Vol 3. New York: Plenum Press, 1979: 373-94.

${ }^{8}$ Nichaman ZM, Reshef A. Attained growth status of selected groups of Israeli children. Am J Clin Nutr 1978; 31: 895-903.

${ }^{9}$ Glick Z, Reshef A. Vitamin A. Status and related nutritional parameters of children in East Jerusalem. Am J Clin Nutr 1973, 26: 1225-33.

${ }^{10}$ Welbourn HF. The danger period during weaning. A study of Baganda children who were attending child welfare clinics near Kampala, Uganda. $J$ Trop Pediatr 1955, 1: 34-98.

${ }^{11}$ Kark SL. Nutrition infection and disease. In: Epidemiology and community medicine. Eaglewood Cliffs, NJ. Appleton Century Crofts, 1974: 249-55.

${ }^{12}$ Gordon JE. In: Beaton GH, Bengoa JM, eds. Synergism of malnutrition and infectious disease in nutrition in preventive medicine. Geneva: WHO, 1976: 193-209.

${ }^{13}$ Afaneh AM. An epidemiological study of haemoglobin levels and weight in children of Salfit West Bank. Jerusalem: Hebrew University, 1974. (MPH thesis.)

${ }^{14}$ Ritchie HSJ. Cultural and psychological influences on food patterns. In: Learning better nutrition. 1967: 30-40. (FAO Nutritional studies of the UN No 20.) Printed in Italy. 